\title{
Cardiovascular system and COVID-19: perspectives from a developing country
}

\author{
Shekhar Kunal' ${ }^{1}$, Kashish Gupta ${ }^{2}$, Shashi Mohan Sharma ${ }^{1}$, Vijay Pathak ${ }^{1}$, Shruti Mittal ${ }^{3}$, \\ Chandrakant Tarke ${ }^{4}$ \\ ${ }^{1}$ Department of Cardiology, Sawai Man Singh Medical College, Jaipur; ${ }^{2}$ Department of Medicine, Sawai Man Singh \\ Medical College, Jaipur; ${ }^{3}$ Department of Radiodiagnosis, Maulana Azad Medical College, New Delhi; ${ }^{4}$ Department of \\ Pulmonology, Apollo Hospital, Jubilee Hills, Hyderabad, India
}

\begin{abstract}
A novel coronavirus, SARS-CoV-2, thought to have originated from bats causes COVID-19 infection which was first reported from Wuhan, China in December 2019. This virus has a high infectivity rate and has impacted a significant chunk of the population worldwide. The spectrum of disease ranges from mild to severe with respiratory system being the most commonly affected. Cardiovascular system often gets involved in later stages of the disease with acute cardiac injury, heart failure and arrhythmias being the common complications. In addition, the presence of cardiovascular co-morbidities such as hypertension, coronary artery disease in these patients are often associated with poor prognosis. It is still not clear regarding the exact mechanism explaining cardiovascular system involvement in COVID-19. Multiple theories have been put forward however, more robust studies are required to fully elucidate the "heart and virus" link. The disease has already made its presence felt on the global stage and its impact in the developing countries is
\end{abstract}

Correspondence: Prof. Vijay Pathak, Department of Cardiology, Sawai Man Singh Medical College, Jaipur, India.

Tel. +91.141.2518261.

E-mail: vijalps2000@yahoo.com

Author contributions: SK, KG, VP, SMS, collected the clinical data, reviewed the literature; SM, reviewed the radiological aspects; CT, reviewed the pulmonary and critical care aspects and reviewed the literature; SK and VP, worked on the concept and are responsible for the genuineness of the data. All the authors have drafted the manuscript and read and approved the final version.

Conflict of interest: the Authors have no conflict of interest to disclose.

Key words: Acute respiratory distress syndrome; arrhythmias;

COVID-19; myocarditis, heart failure.

Received for publication: 13 April 2020.

Accepted for publication: 29 April 2020.

${ }^{\circ}$ Copyright: the Author(s), 2020

Licensee PAGEPress, Italy

Monaldi Archives for Chest Disease 2020; 90:1305

doi: 10.4081/monaldi.2020.1305

This article is distributed under the terms of the Creative Commons Attribution Noncommercial License (by-nc 4.0) which permits any noncommercial use, distribution, and reproduction in any medium, provided the original author(s) and source are credited. going to be profound. These nations not only have a poorly developed healthcare system but there is also a huge burden of cardiovascular diseases. As a result, COVID-19 would adversely impact the already overburdened healthcare network leading to impaired cardiovascular care delivery especially for acute coronary syndrome and heart failure patients.

\section{Introduction}

Severe acute respiratory syndrome Coronavirus- 2 (SARS(oV-2) is a single stranded positive sense RNA virus which belongs to the family Coronaviridae. This novel virus, seventh in its family known to infect humans, is quite similar to its previous counterparts viz. SARS-CoV and MERS-CoV in having a zoonotic origin, human to human transmission and causing acute respiratory distress syndrome (ARDS) [1]. This SARS-CoV-2 had its origin in the city of Wuhan, Hubei province, China and caused ARDS which was declared as pandemic by the World Health Organization (WHO) on March 11, 2020 [2]. With the first case being reported in December 2019, it was just a matter of few days that the virus had made its presence felt globally and had spread to nearly every continent [3]. As of April 8, 2020, a total of 1,760,978 laboratoryconfirmed cases has been documented worldwide with nearly 107,775 fatalities with United States, Spain and Italy being the most affected countries [4]. This rapid spread has been largely attributed to its high infectivity, prolonged asymptomatic phase and uninterrupted global travel [5]. Subsequently, after identification and isolation of this novel virus, the disease was christened as COVID-19 caused by the SARS-CoV-2 [6].

\section{Epidemiology, pathophysiology and clinical presentation}

This novel coronavirus has its origin in bats with Malayan pangolins possibly being the intermediate host and had finally transmitted into humans [1]. The main mode of transmission of SARS-CoV2 is through respiratory droplets leading to person-to-person spread with each infected individual on an average causing 2-3 new infections. The median incubation period in COVID-19 is 5.1 days with a majority of them $(97.5 \%)$ becoming symptomatic within 11.5 days of infection [7]. SARS-CoV-2 infection is caused following binding of viral spike protein to human angiotensin-converting enzyme 2 (ACE2) receptor which is expressed in the lungs (on type 
II pneumocytes), heart, intestine, kidneys and blood vessels. Viral entry occurs by endocytosis following interaction of S1 (spike) glycoprotein with receptor binding domain of ACE receptors. This is followed by release of the viral genome, synthesis of viral structural protein and genome, assembly of mature virions and then release by exocytosis (Figure 1). Immune response following SARS-CoV-2 is responsible both for disease resolution as well as its pathogenesis when this response goes out of control. Multisystem involvement in COVID-19 occurs as a result of the cytokine storm and damage mediated by these inflammatory cytokines. The viral RNA serves as the main pathogenic molecule which binds to the pattern recognition receptors such as Toll-like receptor (TLR) 3, TLR7, TLR8 and TLR9. This leads to triggering of the downstream inflammatory cascade and activation of nuclear factor- $\kappa \mathrm{B}(\mathrm{NF}-\mathrm{\kappa} \mathrm{B})$ and interferon regulatory factor 3 (IRF3) commencing in production of IFN- $\alpha / \beta$ and other pro-inflammatory molecules such as IL-1, IL-2, IL-4, IL-6, IL10 , IL-12, GCSF, IFN- $\gamma$ and TNF- $\alpha$ among which IL-6 is the most important one. This massive production of cytokines leads to increased vascular permeability, alveolar epithelial damage, ARDS followed by multisystem involvement [8].

Respiratory system is predominantly involved in patients with pneumonia with ARDS being the most severe form of presentation.
In the series of 138 patients from Wuhan [9], most common presenting symptoms were fever (99\%), fatigue $(70 \%)$, dry cough $(59 \%)$, anorexia (40\%), myalgias (35\%) and dyspnea (31\%). Dyspnea and fatigue are one of the two common presentations in patients with heart failure and hence it becomes very difficult to distinguish COVID-19 infection in these patients thus adding to the diagnostic dilemma. The spectrum of clinical infection ranges from mild to severe with a majority of them (81\%) having mild symptoms (no pneumonia or mild pneumonia) while severe symptoms (defined as respiratory rate $\geq 30 / \mathrm{min}$, hypoxia: blood oxygen saturation $\leq 93 \%$, $\mathrm{PaO}_{2} / \mathrm{FiO}_{2}<300$, and/or pulmonary infiltrates $>50 \%$ within 24 to 48 h) occurs in $14 \%$. Critical illness (defined as respiratory failure, septic shock, and/or multiple organ dysfunction or failure) have been reported in only $5 \%$ of subjects with overall case fatality rate (CFR) being 2.3\% [10]. Diagnosis is established based on detection of SARS-CoV-2 RNA by reverse-transcription polymerase chain reaction in nasopharyngeal swab or bronchoalveolar lavage [1]. Chest radiography (Figure 2A) usually demonstrates interstitial infiltrates typical of viral infections or consolidation while findings on computed tomography (Figure 2B) includes ground-glass opacification, consolidation in a bilateral and peripheral distribution predominantly involving lower lobes [11].

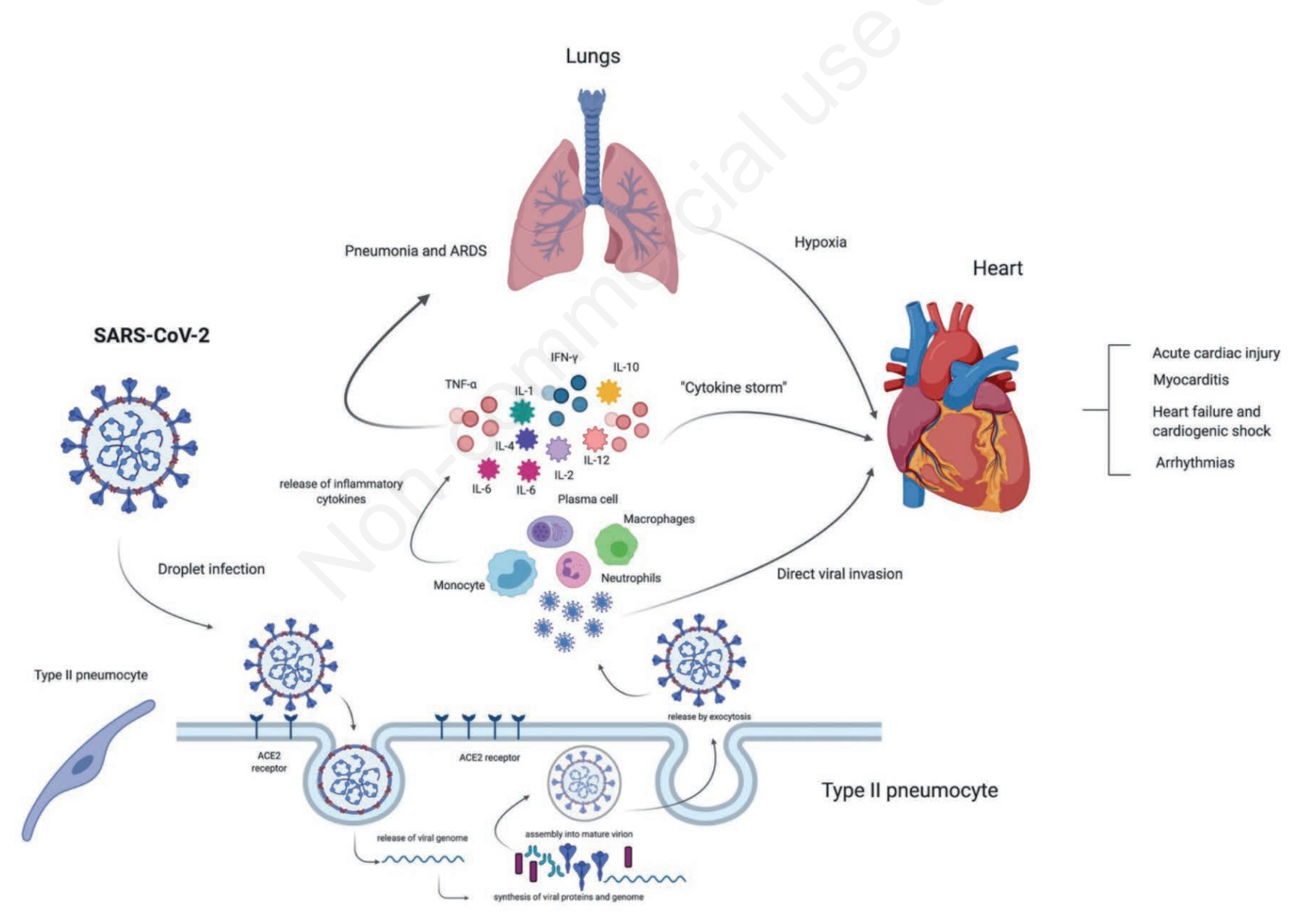

Figure 1. Pictographic representation showing the interaction of SARS-CoV-2 and the host cell as well as the presumed pathways for cardiovascular system being affected. SARS-CoV-2 binds to the ACE-2 receptors on Type II pneumocytes of the lung and undergoes internalization followed by release of viral genome. Following this, utilizing the host cell machinery, viral proteins and genome are synthesized and assembly of mature virions occurs and then are released out of the host cell by exocytosis. Cardiovascular system gets affected either through: i) "cytokine storm" due to interaction of the viral particles and host immune system; ii) viral invasion of the myocardium; iii) hypoxia due to pneumonia and ARDS. ACE2, Angiotensin converting enzyme 2; ARDS, Acute respiratory distress syndrome. Created with BioRender.com. 


\section{COVID-19 and cardiovascular co-morbidities}

Patients with pre-existing co-morbidities tend to be more vulnerable to COVID-19 infection as well as its complications with poor clinical outcomes. A meta-analysis involving 8 studies including 46,248 patients from China reported that most common comorbidities in this population group were hypertension $(17 \pm 7 \%, 95 \% \mathrm{CI}$ : $14-22 \%)$, diabetes $(8 \pm 6 \%, 95 \%$ CI: $6-11 \%)$ and cardiovascular disease (CVD) $(5 \pm 4 \%, 95 \%$ CI: $4-7 \%)$. The odds of hypertension (OR: 2.36, 95\% CI: 1.46-3.83) and CVDs (OR: 3.42, 95\% CI: 1.88-6.22) were higher in severe patients as compared to non-severe group [12]. In one of the largest series of COVID-19 patients $(n=44,672)$, comorbidities such as hypertension were reported in $2683(12.8 \%)$, diabetes in $1102(5.3 \%)$ and CVD in $873(4.2 \%)$ subjects. The case fatality rate (CFR) was higher among patients with co-morbidities such as CVD (10.5\%), diabetes $(7.3 \%)$ and hypertension $(6 \%)$ as compared to those without (CFR:0.9) [10]. Similarly, another study among 1591 patients from Italy reported hypertension (49\%), CVDs (21\%) and hypercholesterolemia (18\%) as common complications in COVID-19 infection [13].

Patients with hypertension were significantly older, required higher PEEP levels, had lower $\mathrm{PaO}_{2} / \mathrm{FiO}_{2}$ and greater in ICU deaths [13]. In the data regarding the mortality in COVID-19 released by the National Health Commission of China, 35\% of patients were hypertensive while $17 \%$ had prior history of CAD [14]. Similar findings were previously observed in SARS pandemic [15] as well as MERS-CoV outbreak [16]. In SARS outbreak, co-morbidities such as diabetes and CVD were reported in $11 \%$ and $8 \%$ subjects respectively with an increased risk of mortality in these groups [15]. Similarly, in MERS-CoV outbreak, diabetes and hypertension were present in nearly half of the cases while CVD in nearly one-third of them [16]. The proposed hypothesis for increased severity of disease in patients with CVDs is that a majority of them are elderly with lower ACE2 levels and higher angiotensin signaling. As SARS-CoV-2 virus binds to ACE2, there occurs a decreased ACE2 expression and hence critically low ACE2 levels leading to higher angiotensin II levels. This leads to a more severe expression of disease in patients with co-morbidities
[17]. The data summarizing the studies on impact of COVID-19 on patients with CV co-morbidities and cardiac complications have been summarized in Table 1 [9-11,13,18-32].

\section{Impact of SARS-CoV-2 on cardiovascular system}

\section{Acute cardiac injury}

In the initial publications from China, myocardial injury as evidenced by high levels of cardiac troponins were being increasingly recognized. In a series of 41 patients from Wuhan, China evidence of myocardial injury (defined as elevated cardiac troponins above the 99 $9^{\text {th }}$ percentile upper reference limit, new abnormalities on ECG or echocardiography) was seen in $5(12 \%)$ with majority of them 4 (80\%) requiring ICU care [18]. Similarly, Wang et al. [9] documented evidence of acute cardiac injury in 10/138 (7.2\%) patients from Wuhan with COVID 19, of whom $8(80 \%)$ required an ICU care. A higher utilization of ICU care among these patients with myocardial injury suggests a more severe and advanced disease process. In a meta-analysis of 341 patients from China (four studies), it was seen that cardiac troponin I levels were significantly higher in patients with severe disease (standardized mean difference $25.6 \mathrm{ng} / 1 ; 95 \% \mathrm{CI}$ [6.8-44.5]). The authors postulated that an early measurement of cardiac troponins immediately post admission would help identify a subset of patients with cardiac injury thus portraying a dismal outcome [33]. A retrospective study from Wuhan, China reported acute cardiac injury in 33/191 (17\%) patients of whom 32 succumbed to the illness. The median time from illness to the development of acute cardiac injury in non-survivors was $14 \cdot 5$ days (9.5-17.0) while among the sole survivor with cardiac injury, the median time was 21 days. Cardiac troponin levels were significantly higher among non-survivors $(p<0.0001)$ [19]. The exact mechanism for myocardial injury has still not been elucidated however, the following possibilities can be considered: i) virus mediated direct myocardial injury, ii) immune mediated myocardial injury, iii) hypoxemia [34]. Viral invasion of the myocardium can be a possibility as SARS-CoV-2 binds to ACE-2 receptors which are also expressed on cardiac myocytes and vascular endothelial cells. This hints at a theoretical possibility of direct car-

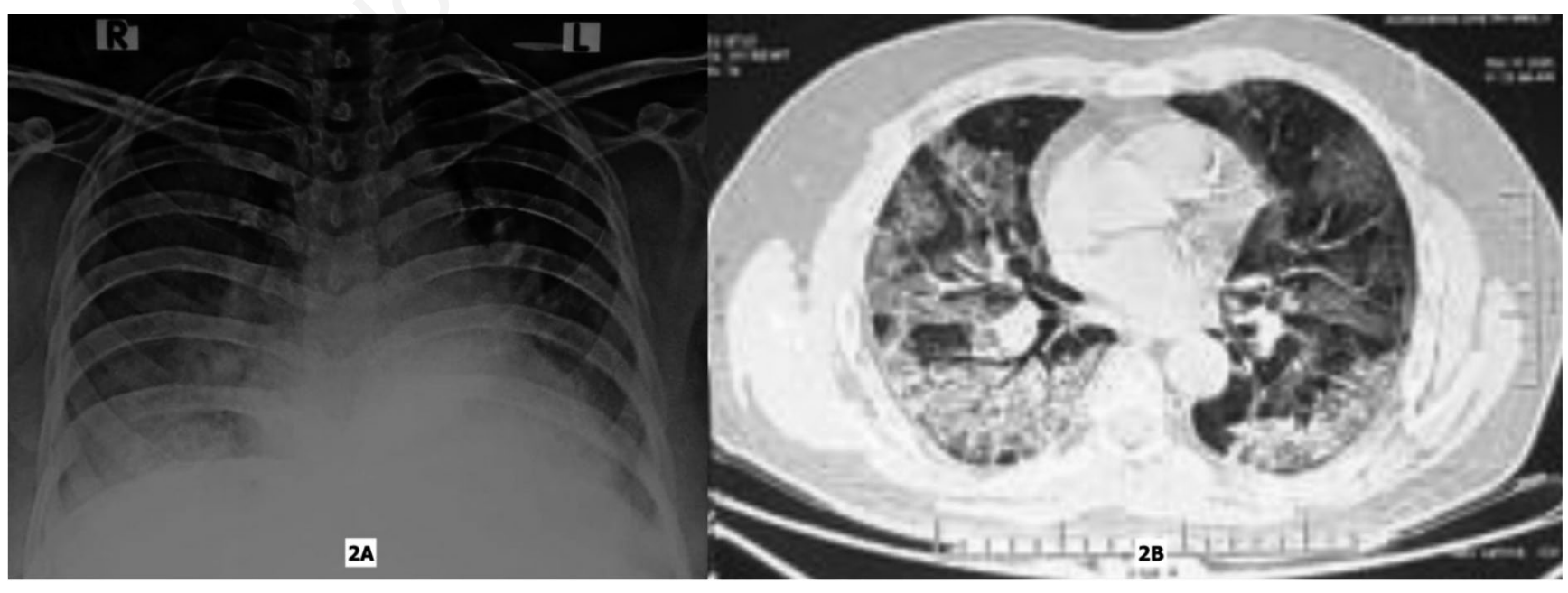

Figure 2. A) Chest radiograph postero-anterior view of a 45-year-old female with hypertension and diagnosed with COVID-19 showing bilateral lower zone infiltrates. B) High resolution computed tomography of the chest of a 47-year-old male showing bilateral ground glass opacities, a finding frequently encountered in COVID-19 positive patients. 
diac involvement by the SARS-CoV-2 virus [34]. However, definite data has been lacking with an autopsy-based case report documenting few mononuclear inflammatory infiltrates in myocardial interstitium on cardiac biopsy in a 50-year-old male who had succumbed to COVID-19 [35]. Another recent report from Italy documented the presence of low grade myocardial inflammation and viral particles in the myocardium (electron microscopy) on endomyocardial biopsy in a 69-year-old male with COVID-19 and cardiogenic shock [36]. Immune mediated myocardial injury can be a part of the cytokine storm associated with COVID-19 disease. Various inflammatory cytokines such as IL-6 and TNF-alpha have been associated with a negative inotropic effect. In addition, cytokine mediated myocardial injury is also another possibility in these cases [37]. In a retrospective series of 54 patients with COVID-19, CRP levels were higher in patients with myocardial injury than those without indicating a severe inflammatory response in the former group [38]. Thirdly, hypoxemia as a part of respiratory failure in these patients may lead to myocardial oxygen demand supply mismatch especially in those with preexisting cardiac disease culminating in myocardial damage. Two patterns of myocardial injury have been reported in patients with
COVID-19 disease. The first pattern reflects cytokine mediated cardiac injury where in the levels of cardiac troponins increase simultaneously with inflammatory cytokines such as IL-6 as a part of the cytokine storm. These patients have an increased vascular permeability as well as myocardial edema. The other pattern is reported in patients presenting predominantly with cardiac symptoms reflecting viral myocarditis or stress induced cardiomyopathy [34].

\section{Myocarditis in COVID-19}

Myocarditis can be one of the clinical presentations in COVID 19 however, its exact pathogenesis is still not clear. Viral infections such as those associated with influenza and parvovirus B-19 have been widely considered as one of the common causes of myocarditis [34]. Viral myocarditis may present as either "focal or global myocardial inflammation, necrosis, and ventricular dysfunction". The data on the incidence of fulminant myocarditis in COVID-19 is very much limited. Zeng et al. [39] reported the first case of COVID-19 presenting with fulminant myocarditis in a 63-year-old male with no underlying cardiac disease. On admission, cardiac enzymes (troponin-I: 11.37 $\mathrm{g} / \mathrm{l}$, myoglobin: $390.97 \mathrm{ng} / \mathrm{ml}$ ) and N-terminal brain natriuretic pep-

Table 1. Table documenting COVID-19 case series reporting patients with cardiovascular co-morbidities and complication and its impact on outcomes.

\begin{tabular}{|c|c|c|c|c|}
\hline Authors/ Country & $\begin{array}{l}\text { No. of patients } \\
\text { (N)/Age/Sex }\end{array}$ & $\begin{array}{l}\text { Cardiovascular } \\
\text { co-morbidities }\end{array}$ & Cardiac complications & $\begin{array}{l}\text { Co-morbidities/complication } \\
\text { association with outcomes }\end{array}$ \\
\hline Wang et al. [9], China & $\begin{array}{c}\mathrm{N}=138 / \text { median age: } \\
56 \text { years/males: } \\
75(54.3 \%)\end{array}$ & $\begin{array}{c}\text { Hypertension: } 43(31.2 \%) \\
\text { CVD: } 20(14.5 \%) \\
\text { Diabetes: } 14(10.1 \%) \\
\text { CVA: } 7(\%)\end{array}$ & $\begin{array}{c}\text { Arrhythmia: } 16(11.6 \%) \\
\text { Shock*: } 11(7.9 \%) \\
\text { Acute cardiac injury: } 10 \text { (7.2\%) }\end{array}$ & $\begin{array}{l}\text { CV co-morbidities and } \\
\text { complications increased } \\
\text { CU admissions }\end{array}$ \\
\hline $\begin{array}{l}\text { Wu and McGoogan [10], } \\
\text { China }\end{array}$ & $\begin{array}{l}\mathrm{N}=44,672 / \text { mean or } \\
\text { median age: } \\
\text { NR } / \text { males: } \\
22,981(51.4 \%)\end{array}$ & $\begin{array}{l}\text { Hypertension: } 2683(12.8 \%) \\
\text { Diabetes: } 1102(5.3 \%) \\
\text { CVD: } 873(4.2 \%)\end{array}$ & NR & $\begin{array}{l}\text { CFR elevated among those } \\
\text { with pre-existing comorbid } \\
\text { conditions: } 10.5 \% \text { for CVD, } \\
7.3 \% \text { for diabetes and } 6.0 \% \\
\text { for hypertension }\end{array}$ \\
\hline Shi Het al. [11], China & $\begin{array}{c}\text { N=416/median age: } \\
64 \text { years/males: } \\
195(46.8 \%)\end{array}$ & $\begin{array}{l}\text { Hypertension: } 127(30.5 \%) \\
\text { Diabetes: } 60(14.4 \%) \\
\text { CAD: } 44(10.6 \%) \\
\text { CVA: } 22(5.3 \%)\end{array}$ & $\begin{array}{l}\text { Acute cardiac injury: } 82(19.7 \%) \\
\text { Heart failure: } 17(4.1 \%)\end{array}$ & $\begin{array}{l}\text { High risk of mortality in patients } \\
\text { with acute cardiac injury }\end{array}$ \\
\hline Grasselli et al. [13], Italy & $\begin{array}{l}\mathrm{N}=1591 / \text { median age: } \\
63 \text { years/males: } \\
1304(82 \%)\end{array}$ & $\begin{array}{c}\text { Hypertension: } 509 \text { (49\%) } \\
\text { CVD: } 223 \text { (21\%) } \\
\text { Hypercholesterolemia: } 188 \text { (18\%) }\end{array}$ & NR & $\begin{array}{l}\text { Higher mortality in hypertensive } \\
\text { patients }\end{array}$ \\
\hline Huang et al. [18], China & $\begin{array}{l}\mathrm{N}=41 / \text { median age: } \\
49 \text { years/males: } \\
30(71 \%)\end{array}$ & $\begin{array}{l}\text { Diabetes: } 8(20 \%) \\
\text { Hypertension: } 6(15 \%) \\
\text { CVD: } 6(15 \%)\end{array}$ & Acute cardiac injury: 5 (12\%) & NR \\
\hline Zhou et al. [19], China & $\begin{array}{l}\mathrm{N}=191 / \text { median age: } \\
\text { 56/males: } 119(62 \%)\end{array}$ & $\begin{array}{l}\text { Hypertension: } 58 \text { (30\%) } \\
\text { Diabetes: } 36(19 \%) \\
\text { CAD: } 15(8 \%)\end{array}$ & Acute cardiac injury: 33 (17\%) & $\begin{array}{l}\text { CV co-morbidities and acute cardiac } \\
\text { injury: higher in non-survivors }\end{array}$ \\
\hline Guo et al. [20], China & $\begin{array}{l}\mathrm{N}=187 / \text { mean age: } \\
58.5 \pm 14.6 / \text { males: } \\
91(48.7 \%)\end{array}$ & $\begin{array}{l}\text { Hypertension: } 61(32.6 \%) \\
\text { Diabetes: } 28(15 \%) \\
\text { CVD: } 21(11.2 \%) \\
\text { Cardiomyopathy: } 8(4.3 \%)\end{array}$ & $\begin{array}{c}\text { Myocardial injury: } 52 \text { (27.8\%) } \\
\text { Arrhythmias: VTNF - } 11 \text { (5.8\%) }\end{array}$ & $\begin{array}{l}\text { High risk of mortality in patients } \\
\text { with higher cardiac troponins }\end{array}$ \\
\hline Guan et al. [21], China & $\begin{array}{c}\text { N=1099/median age: } \\
47 \text { years/males: } \\
637(58.1 \%)\end{array}$ & $\begin{array}{c}\text { Hypertension: } 165(15 \%) \\
\text { Diabetes: } 81(7.3 \%) \\
\text { CAD: } 27(2.5 \%) \\
\text { CVA: } 15(1.4 \%)\end{array}$ & NR & $\begin{array}{c}\text { Higher prevalence of CV } \\
\text { co-morbidities in severe disease }\end{array}$ \\
\hline Chen et al. [22], China & $\begin{array}{c}\mathrm{N}=99 / \text { mean age: } \\
55.5 \pm 13.1 \text { years/males: } \\
67(68 \%)\end{array}$ & $\begin{array}{l}\text { Co-morbidities: } 50 \\
\text { (details NA) }\end{array}$ & $\begin{array}{l}\text { Heart failure: } 1(1 \%) \\
\text { Cardiac arrest: } 1(1 \%)\end{array}$ & NR \\
\hline
\end{tabular}


tide (NT BNP: $22600 \mathrm{pg} / \mathrm{ml}$ ) were elevated. ECG was suggestive of sinus tachycardia with no ST elevation. Echocardiography revealed enlarged cardiac chambers, dyskinetic myocardium with decreased LVEF (32\%). The patient was initiated on anti-viral therapy, intravenous corticosteroids, immunoglobulins and ultimately placed on an ECMO following which there was a remarkable recovery with improvement in his LVEF to $68 \%$. Similarly, Hu and colleagues [40] reported a 37-year-old male who presented with acute onset chest pain and hypotension with ST elevation in inferior leads and raised cardiac enzymes and BNP. CT coronary angiography revealed normal epicardial coronaries while echocardiography was suggestive of enlarged cardiac chambers, severely decreased ventricular function (LVEF: 27\%) with minimal pericardial effusion. Tests for COVID-19 were positive while samples for other viruses causing myocarditis were negative. Patient was initiated on intravenous corticosteroids, immunoglobulins, inotropic support along with broad spectrum antibiotics following which he had a marked improvement (LVEF: $66 \%$ prior to discharge). Recently, Hua et al. [41] reported life-threatening cardiac tamponade due to viral myopericarditis as a result of COVID-19 infection in a 47-year-old female. Most of the diagnoses of myocarditis have been made based on clinical and ECG findings, elevated cardiac enzymes, echocardiographic evidence with normal coronaries on coronary angiogram [39-41]. These is a limited data on use of cardiac magnetic resonance (CMR) in these patients with a single report describing a 53-year-old male presenting with acute myopericarditis. CMR was suggestive of increased ventricular wall thickness, diffuse hypokinesia of both ventricles and LV systolic dysfunction (LVEF: 35\%). CMR sequences such as short tau inversion recovery (STIR) and T2-mapping revealed marked "myocardial interstitial edema" in both the ventricles along with diffuse late gadolinium enhancement involving entire biventricular wall [42]. Since endomyocardial biopsy was not carried out in these patients and no effort was made to demonstrate viral genome in the affected myocardium our understanding of the disease process is greatly hampered [42]. Similar findings were reported on CMR in myocarditis caused by MERS CoV [43]. In a retrospective study of 84 patients with COVID from China, the prevalence of clinically diagnosed SARS-CoV-2 myocarditis was 4.8\%. However, a major limitation of this study was absence of echocardiography, CMR or endomyocardial biopsy for diagnosis of myocarditis [44].

Table 1. Continued from previous page.

\begin{tabular}{lcccc} 
Authors/ Country & No. of patients & Cardiovascular & Cardiac complications & $\begin{array}{c}\text { Co-morbidities/complication } \\
\text { association with outcomes }\end{array}$ \\
Yang et al. [23], China & N=52/mean age: & Diabetes: $9(17 \%)$ & Acute cardiac injury: 12 (23\%) & Higher prevalence of CV \\
& $59.7 \pm 13.3$ years/males: & CVA: $7(13.5 \%)$ & & co-morbidities in non-survivors \\
& $35(67 \%)$ & CVD: $5(10 \%)$ & & \\
\hline Chen et al. [24], China & N=274/median age: & Hypertension: $93(34 \%)$ & Acute cardiac injury: $89 / 203(44 \%)$ & CV co-morbidities, acute cardiac \\
& 62 years/males: & Diabetes: $47(17 \%)$ & Heart failure: $43 / 176(24 \%)$ & injury, BNP and cardiac troponins: \\
& $171(62 \%)$ & CVD: $23(8 \%)$ & Shock: $46 / 274(17 \%)$ & higher in deceased patients
\end{tabular}

Heart Failure: $1(<1 \%)$

CVA: 4 (1\%)

\begin{tabular}{|c|c|c|c|c|}
\hline Yang et al. [25], China & $\begin{array}{c}\mathrm{N}=149 / \text { mean age: } \\
45.11 \pm 13.35 / \text { males: } \\
81(54.3 \%)\end{array}$ & CVD: 28 (18.8\%) & None & None \\
\hline Xu et al. [26], China & $\begin{array}{c}\mathrm{N}=62 / \text { median age: } \\
\text { 41/ males: } 35(56 \%)\end{array}$ & $\begin{array}{c}\text { Hypertension: } 5(8 \%) \\
\text { Diabetes: } 1 \text { (\%)CVA: } 1 \text { (\%) }\end{array}$ & NR & NR \\
\hline Zhang et al. [27], China & $\begin{array}{l}\mathrm{N}=140 / \text { median age: } \\
\text { 57/males: } 71(50.7 \%)\end{array}$ & $\begin{array}{c}\text { Hypertension: } 42 \text { (30\%) } \\
\text { Diabetes: } 17(12.1 \%) \\
\text { CAD: } 7(5 \%) \\
\text { Arrhythmias: } 5 \text { (3.6\%) }\end{array}$ & NR & $\begin{array}{l}\text { No significant association between } \\
\text { CV co-morbidities and severity } \\
\text { of the disease }\end{array}$ \\
\hline Bhatraju et al. [28], USA & $\begin{array}{l}\mathrm{N}=24 / \text { mean age: } \\
64+18 \text { vears/males: }\end{array}$ & $\begin{array}{c}\text { Diabetes: } 14(58 \%) \\
\text { CVA: } 2(8 \%)\end{array}$ & Shock*: 17 (71\%) & None \\
\hline
\end{tabular}

64+18 years/males: $\quad$ CVA: $2(8 \%)$ $15(63 \%)$

\begin{tabular}{lcccc} 
Arentz et al. [29], USA & N=21/mean age: & Heart Failure: $9(42.9 \%)$ & Cardiomyopathy: $7(33.3 \%)$ & None \\
& $\begin{array}{l}70 \text { years/males: } \\
11(52 \%)\end{array}$ & Diabetes: $7(33.3 \%)$ & & \\
\hline Ruan et al. [30], China & N=150/mean age: & Hypertension: $52(34.7 \%)$ & Five patients (7\%) with & CV co-morbidities, acute cardiac \\
& NR/males: & Diabetes: $25(16.7 \%)$ & myocardial damage died of & injury and cardiac troponins: \\
& $102(68 \%)$ & CVD: $13(8.6 \%)$ & circulatory failure, & higher in deceased patients
\end{tabular}

died of respiratory failure + myocardial damage

\begin{tabular}{|c|c|c|c|c|}
\hline Fang et al. [31], China & $\begin{array}{c}\text { N=3470/mean age: } \\
\text { NR/males: } \\
1822(52.6 \%)\end{array}$ & $\begin{array}{c}\text { Hypertension: } 376 / 2818(13.3 \%) \\
\text { CVD: } 233 / 2818(8.3 \%) \\
\text { Diabetes: } 206(7.3 \%)\end{array}$ & NR & NR \\
\hline Wu et al. [32], China & $\begin{array}{c}\mathrm{N}=201 / \text { median age: } \\
51 \text { years/males: } \\
128(63.7 \%)\end{array}$ & $\begin{array}{c}\text { Hypertension: } 39(19.4 \%) \\
\text { Diabetes: } 22(10.9 \%) \\
\text { CVD: } 8(4 \%)\end{array}$ & NR & $\begin{array}{c}\text { Patients with ARDS: } \\
\text { higher frequency } \\
\text { of hypertension and diabetes }\end{array}$ \\
\hline
\end{tabular}




\section{Arrhythmias}

Cardiac arrhythmias both tachy- as well as brady- arrhythmias are common in patients with COVID-19. In one of the earliest series, Wang et al. [9] reported prevalence of cardiac arrhythmias in 23/138 (16.7\%) patients of whom $16(44.4 \%)$ required ICU care. However, type and duration of cardiac arrhythmias in these patients were not detailed. In another study, Hui and colleagues [45] reported ECG findings in 17/41 patients, of whom three had tachycardia with a higher prevalence in severe and critical cases. Atrial fibrillation was reported in two patients with critical illness both of whom had a fatal outcome. Guo et al. [20] reported ventricular tachycardia/ventricular fibrillation in 11/187 (5.9\%) patients with SARS-CoV-2 infection. Patients with elevated cardiac troponins had a significantly higher frequency of malignant arrhythmias compared to those without ( 9 vs $2 ; \mathrm{p}<0.001)$. This highlighted the fact that patients with myocardial injury had far greater prevalence of tachyarrhythmias. A high frequency of arrhythmias may be in part due to metabolic causes such as electrolyte disturbances, neurohormonal activation or hypoxia especially in those who are critically ill. Similar findings have been documented in previous SARS pandemic with tachycardia being most common finding seen in $2 / 3^{\text {rd }}$ of patients. The authors had also reported that the potential of SARS-CoV to lead to cardiac arrhythmias was very low [46].

\section{Drug induced cardiac arrhythmias}

As the COVID-19 pandemic has widened its grip, "off label" re-purposing of various drugs such as hydroxychloroquine (HCQ), azithromycin and lopinavir/ritonavir has been done in a bid to halt its march. However, with the usage of these drugs there has been the inadvertent risk of QT prolongation, torsades de pointes (TdP) and sudden cardiac death. HCQ has shown promising results in in vitro studies and is being increasingly used both for treatment as well as post-exposure chemoprophylaxis [47]. HCQ mainly acts by (a) inhibiting ACE2-mediated viral entry hence preventing SARSCoV-2 infection and (b) anti-inflammatory and immunomodulatory property hence attenuating the cytokine storm. However, due to its inherent property of blocking the $\mathrm{hERG} / \mathrm{Kv} 11.1$ potassium channel, it can prolong the QT interval and increase risk of TdP especially in patients with congenital long QT syndrome [47]. This risk further gets compounded when drugs such as azithromycin or lopinavir and ritonavir are prescribed simultaneously with HCQs.

A baseline 12-lead electrocardiogram should be performed in all COVID-19 positive patients planned to receive these drugs along with serial monitoring in those with prolonged QTc interval. In a bid to decrease exposure to ECG technicians, mobile ECG devices such as KardiaMobile-6L device has received FDA clearance for QT monitoring in COVID-19 patients [47]. In addition, renal and hepatic functions, serum electrolytes should also be measured. In patients with QTc values $<99^{\text {th }}$ percentile for age/gender (460 ms in pre-pubertal males/females, $470 \mathrm{~ms}$ in postpubertal males, and $480 \mathrm{~ms}$ in postpubertal females) there is a low risk of TdP and hence drugs such as HCQ/chloroquine, lopinavir ritonavir or azithromycin can be initiated without delay. In patients with QTc $>500 \mathrm{~ms}$, a search should be made to identify all correctable cause of prolonged QT (drugs, electrolytes) and a riskbenefit analysis should be done prior to start of therapy. If these patients are started on such drugs, it is recommended to use HCQ alone rather than a combination with azithromycin and frequently monitor the QTc intervals. In patients with QTc values $<99^{\text {th }}$ percentile for age/gender prior to therapy and while on treatment, the QTc $>500 \mathrm{~ms}$ or QTc increases by $>60 \mathrm{~ms}$, azithromycin should be discontinued and or dose of hydroxychloroquine be reduced followed by daily ECG. If despite this, the QTc $>500 \mathrm{~ms}$, it is prudent to perform a risk-benefit analysis in order to discontinue $\mathrm{HCQ}^{47}$.

\section{Heart failure and cardiogenic shock}

In a retrospective cohort study from China, Zhou et al. [19] reported heart failure in 44/191 (23\%) patients with a significant proportion of non-survivors having heart failure (52\% vs $21 \%$; $\mathrm{p}<0.001)$. A varied etiology including acute coronary syndrome (ACS), structural heart disease, arrhythmias, stress cardiomyopathy may be responsible for de-novo or worsening of pre-existing heart failure. In a small study involving 21 patients from United States, Arentz and colleagues [29] reported development of cardiomyopathy in $7(33 \%)$ of the patients. Cardiomyopathy in this group was defined as global decrease in left ventricular systolic function on transthoracic echo (TTE) along with evidence of clinical features of cardiogenic shock, elevated cardiac enzymes, decreased central venous $\mathrm{O}_{2}$ saturation $<70 \%$ without any antecedent history of systolic dysfunction [29]. It is still not clear regarding contribution of right heart failure in these patients especially those with advanced disease and ARDS in absence of hemodynamic data. Bedside TTE does form an important armamentarium in diagnosis and management of these patients especially those with heart failure. Another critical condition which warrants our attention are the patients presenting with hemodynamic compromise and shock. It is one of the utmost priorities to differentiate cardiogenic from septic shock in these patients. This is especially useful in deciding the choice of mechanical circulatory support (veno-arterial versus veno-venous ECMO) and need for left ventricular unloading. However, at times it becomes difficult especially in patients with sepsis, ARDS and myocarditis and left ventricular dysfunction and patients can present in a "mixed shock" state ${ }^{48}$.

\section{Venous thrombo-embolism}

Patients with COVID-19 disease are at a high risk of venous thrombo-embolism (VTE) especially those patients who are critically ill with prolonged immobilization. Apart from venous stasis as a result of prolonged immobilization, hypercoagulability due to use of glucocorticoid, immunoglobulins as well as vascular endothelial damage due to central venous catheterization and/or ECMO often are a contributing factor for occurrence of VTE. Hypoxia too has been postulated as one of the causes of hypercoagulable states in these patients. Although none of the studies have reported a prevalence of VTE, few case reports have mentioned the occurrence of pulmonary embolism in these patients. Xie et al. [49] reported occurrence of acute pulmonary embolism in two patients aged 57 and 70 years with elevated D-dimer and multiple filling defects on CT pulmonary angiogram. Similarly, Danzi et al. [50] too reported a 75-year-old female with pulmonary embolism and TTE finding of right ventricular dysfunction. Multiple studies from China have reported higher D-dimer levels in COVID-19 patients with adverse outcomes. Zhou et al. [19] reported elevated D-dimer levels which was strongly associated with a greater in-hospital mortality (OR: $18.4 ; \mathrm{p}=0.003)$. Similarly, another study showed that in non-survivors, D-dimer levels were significantly higher than survivors $(2.12$ $\left.\mu \mathrm{g} / \mathrm{ml} v_{s} 0.61 \mu \mathrm{g} / \mathrm{ml} ; \mathrm{p}<0.001\right)$ thus reflecting a worse prognosis. A majority of the non-survivors had met the criteria for DIC [51]. Multiple reasons can be postulated for activation of coagulation cascade in critically ill-patients which include i) pro-inflammatory cytokines lead to activation of coagulation cascade especially in critically ill patients and D-dimer is a marker of fibrinolytic activity [52]; ii) during inflammatory conditions, the alveolar hemostatic 
balance is tilted more towards a prothrombotic state [53]; iii) proinflammatory cytokines may itself lead to endothelial injury and activation of coagulation cascade [54]. In such a scenario, levels of D-dimer which serves as marker of fibrinolytic activity is elevated along with other inflammatory cytokines.

Critically ill patients with COVID-19 are at an increased risk for venous thrombosis and hence the need for anticoagulation in these patients. In the Chinese cohort of COVID-19 patients, an early use of anticoagulation was initially recommended [55]. Ddimer has a limited predictive value for venous thromboembolism especially in critically ill and hospitalized patients hence, VTE risk assessment should be done on an individualized basis. Another factor to be considered regarding anticoagulation is that most of the patients are elderly with multiple comorbid conditions hence an increased bleeding risk. A recent study showed that in COVID-19 positive patients with sepsis-induced coagulopathy score $<4$, administration of heparin led to a reduced 28-day mortality. This showed that anticoagulant therapy had better outcomes in only selected group of patients [56]. Anticoagulation with heparin thus has been recommended by few experts in China based on the limited data $[55,57]$.

\section{COVID-19 and STEMI}

During these testing times, balancing cardiovascular emergencies with COVID care has become a huge challenge. Patients with STEMI presenting to emergencies require two things: i) management in a safe environment, and ii) an effective reperfusion strategy. For patients with ACS, recommendations vary between the Chinese [58] and their American counterparts [59]. Authors from China [58] have recommended that in STEMI patients with confirmed/suspected COVID-19 and presentation within $12 \mathrm{~h}$, strict isolation followed by thrombolysis if no contraindication exists. In case of late presenters with ongoing symptoms, hemodynamic instability, arrhythmias or contraindication for thrombolysis or failed thrombolysis, patients to undergo risk versus benefit assessment followed by catheterization with proper personal protective measures. Patients with NSTEMI and hemodynamically stable with low/intermediate risk to undergo medical management followed by PCI post COVID-19 treatment. In high risk NSTEMI patients, risk versus benefit analysis to be done followed by PCI with strict isolation [58]. The ACC/SCAI joint statement [59] called for primary PCI in all STEMI patients as well as unstable NSTEMI patients after adequate personnel protective measures. It also called for deferring elective procedures such as PCI for stable angina in order to preserve hospital bed capacity.

In a study detailing the impact of COVID-19 on STEMI care showed that there was a significant increase in time components such as symptom onset to first medical contact, door to device and Catheterization laboratory arrival to device. The largest increase was observed in time from symptom onset to first medical contact. These could be explained based on the fact that i) people are often hesitant to visit a hospital during the outbreak thus leading to a pre-hospital delay or seeking no care at all; ii) delay in the hospital attributed to detailed evaluation in the emergency department including travel and contact history, upper airways symptoms and chest radiograph prior to shifting to catheterization laboratories; iii) infection control measures including patient preparation, time consumed in wearing protective gears. These problems could be further compounded in low resource countries especially during periods of lockdown with poor health care facilities at peripheral hospitals [60].

\section{COVID 19 and valvular heart disease}

A significant chunk of valvular heart disease patients both rheumatic or non-rheumatic are found in developing countries. In the previous influenza pandemics since 1918, viral pneumonias were predominantly seen in patients with rheumatic heart disease especially mitral stenosis [61]. However, there are no published studies regarding the impact of COVID-19 on patients with preexisting valvular heart diseases. With most of the structural heart disease interventions/cardiac surgeries being postponed, it is the decision of the heart team regarding the treatment protocol of more symptomatic patients. Urgent cardiovascular intervention/cardiac surgery are reserved only for few subsets of patients such as those with i) severe aortic stenosis and syncope, uncontrolled heart failure or ejection fraction $<50 \%$, and ii) severe chronic mitral regurgitation and uncontrolled heart failure despite optimal medical therapy or left ventricular dysfunction [62].

\section{ACE inhibitors/ARBs usage in COVID-19 patients}

In an article published in the British Medical Journal, Sommerstein and Gräni [63] put forward a hypothesis regarding the potential role of ACE inhibitors/ARBs in increasing susceptibility to SARS-CoV-2. Data from the Chinese registries have pointed out that hypertension, diabetes and coronary artery disease are the most common cardiac complications in the COVID-19 population and a substantial population of them are prescribed ACE inhibitors or ARBs. Some authors went further ahead and speculated that ACE inhibitors or ARBs are responsible for worsening of COVID-19 cases and even proposed for replacement of these drugs with other antihypertensive agents [64]. These articles fueled a controversy creating a panic among healthcare providers as well as the patients.

This controversy stems from the fact that surface spike proteins of SARS-CoV-2 binds to target cells through angiotensin-converting enzyme 2 (ACE2) receptors, which are expressed in the oral mucosa, type II pneumocytes in lung, epithelial cells of intestine, and vascular endothelium. ACE 2 serves as the key enzyme for the breakdown of angiotensin II to angiotensin-(1-7) hence decreasing the effects of angiotensin II such as vasoconstriction, sodium retention and fibrosis. Despite there being a structural similarity between $\mathrm{ACE}$ and ACE2, the enzymatic active sites are quite different and hence ACE inhibitors do not have an impact on ACE2 activity [65]. The authors who had proposed the hypothesis of an adverse impact of RAAS inhibition in these patients had speculated regarding the upregulation of ACE 2 receptors by ACE inhibitors or ARBs in diabetic/hypertensive patients [64]. Few animal models have shown varying results regarding the use of ARBs on ACE2 with limited data in humans studying the effects of RAAS inhibition on ACE2 expression [65]. In fact, there is a potential benefit rather than harm with the use of ACE inhibitors in these patients. Post binding of the SARS-CoV-2 to the ACE 2 receptors, there occurs a downregulation of ACE2 expression leading to increased levels of angiotensin II, local RAAS activation and hence the deleterious effect (Figure 3). This was evident from a small study among 12 patients wherein it was seen that plasma levels of angiotensin II in COVID-19 patients was markedly elevated as compared to healthy controls and had a linear association with viral load and lung injury [66]. Studies previously done in mice showed that ARBs such as losartan can mitigate the effects of acute lung injury induced by SARS-CoV [67] and H5N1 influenza virus A [68]. 
With all these uncertainties and multiple theories regarding the role of RAAS inhibition in COVID-19 infection, withdrawal of ACE inhibitors/ARBs would lead to more harm than benefit in critically ill patients with multiple comorbidities. Since COVID-19 infection is more severe in patients who are diabetics, hypertensives, heart failure RAAS inhibitors clearly have an upper hand in these subsets of patients. As a result, various cardiovascular societies such as European Society of Cardiology have come forward and issued statements regarding continuation of $\mathrm{ACE}$ inhibitors/ARBs in these patients [69]. The International Society of Hypertension (ISH) [70] further endorsed the statements by the Council on Hypertension of the European Society of Cardiology and the European Society of Hypertension which made it clear that "there was no substantial evidence to suggest avoidance of ACEinhibitors or ARBs for the management of hypertension in COVID-19 patients". ISH also stressed on the fact that there are no clinical data in humans to implicate ACE-Inhibitors or ARBs in either improvement or worsening of COVID-19 cases nor does it lead to increased susceptibility to COVID-19 infections.

\section{COVID 19 and heart transplant}

Patients who have undergone Solid organ transplantation including heart transplant are at an increased risk for SARS-CoV-
2 infections owing to a greater degree of immunosuppression. In the initial reports, $\mathrm{Li}$ and colleagues [71] reported the disease course and outcomes in two patients (one with mild and other with severe manifestations) with microbiologically confirmed COVID19 disease. A favorable outcome was reported in both of these cases. It has been postulated that patients who have undergone heart transplant and taking precautionary measures may be at a lower risk. Most of these patients are at an inherent risk of infectious diseases and hence practice social distancing, follow adequate sanitization measures and good hand hygiene. A study detailing the epidemiological and clinical characteristics of heart transplant recipients during COVID-19 outbreak in Wuhan, China showed that those patients who had followed preventive measures including wearing of a mask, hand hygiene and sanitization had lower infection rates. Of the 87 heart transplant cases, 79 recipients were residents of Hubei province while 57 recipients had a history of travel to Wuhan, the epicenter of the outbreak. Upper airway infection was seen in only 4 patients of whom 3 were negative for SARS-CoV-2 while one was not tested with uneventful recovery in all. A majority of these patients $(96.6 \%)$ undertook precautionary measures in the community while $64.4 \%$ had self-quarantined at home. The authors also proposed that apart from proper sanitization measures, a difference in ACE2 expression in the lung might exist in presence of immunosuppression explaining lower rates of COVID-19 infection [72]. Another group of patients who might be at risk are those awaiting cardiac transplantation. There can be a

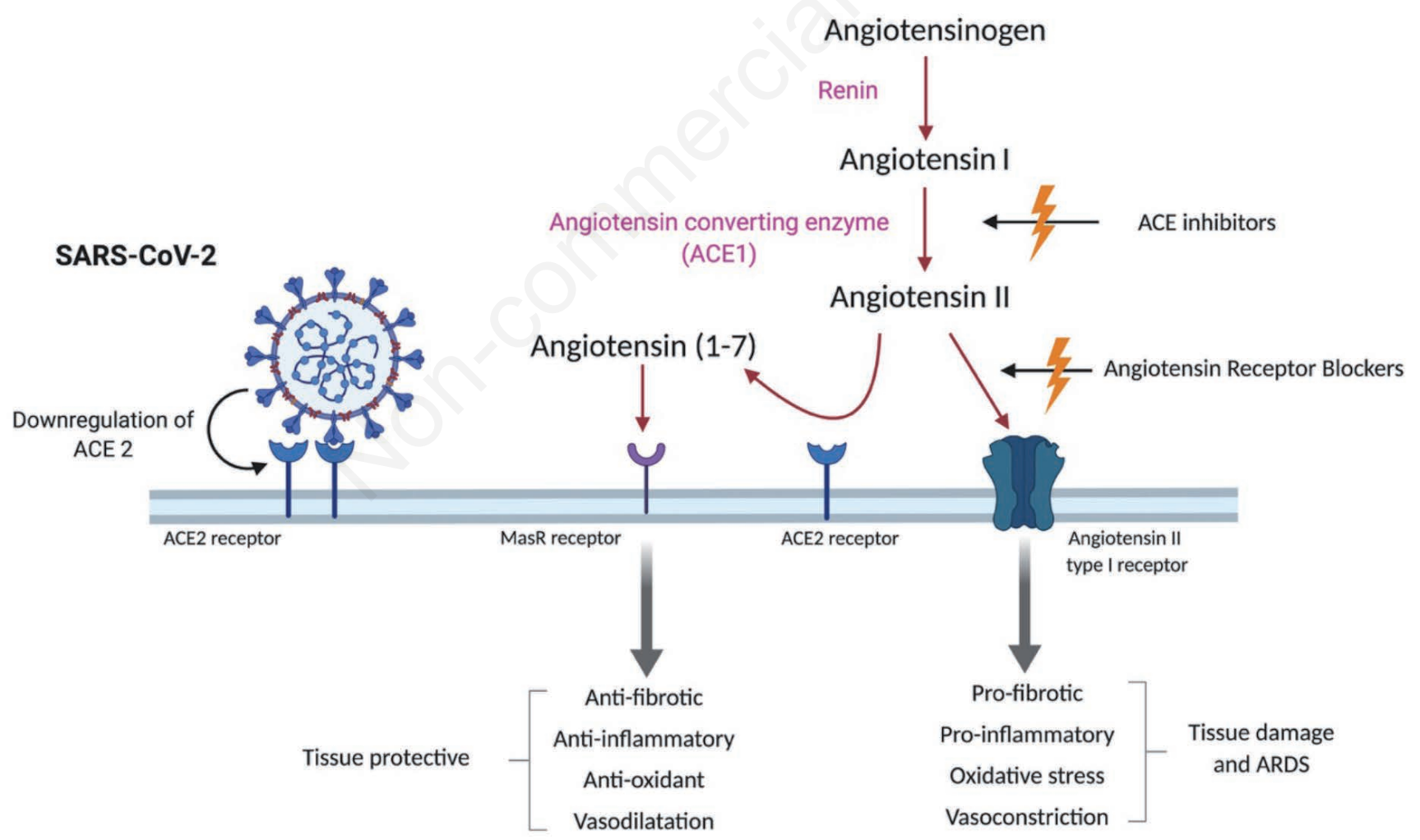

Figure 3. Pictographic representation showing the role of ACE inhibitors and ARBs in COVID-19 patients. Angiotensinogen is degraded into angiotensin I by renin while angiotensin I gets converted to angiotensin II by ACE1 enzyme in the lung. Angiotensin II acting through the AT1 receptors serves as a potent vasoconstrictor, pro-inflammatory; pro-fibrotic leading to tissue damage and ARDS. Angiotensin II is degraded by ACE2 into angiotensin (1-7) which through MAS receptors act as vasodilator, anti-inflammatory and anti-fibrotic and is responsible for tissue protection. ACE2 in the type II pneumocytes serves as a receptor for SARS-CoV-2. Use of ACE inhibitors or ARBs decreases the levels of or binding of angiotensin II to its receptors and hence prevents the adverse effects of angiotensin II andserves as tissue protective. ACE2, angiotensin converting enzyme 2; AT1, angiotensin I. Created with BioRender.com. 
potential risk of transmission through the donor to the recipient however there is no definite evidence to support this claim. In addition, it is still not clear regarding the assessment of organ donors for transplantation during the current pandemic and its impact on the transplant teams and recipient.

\section{COVID-19 and cardiovascular system in developing countries}

The impact of COVID-19 in low- and middle-income countries is expected to be huge. With an already overburdened healthcare system, it shall be a colossal challenge in dealing with this pandemic especially in resource limited setups. In such a scenario, managing CVDs shall take a setback as majority of the resources and manpower have been diverted for COVID care. CVD still remains one of the world's biggest killer. Older patients with coronary artery disease, diabetes and hypertension are at a high risk of mortality due to COVID-19. Hence, strict control measures such as social distancing, lockdown and curfews are the need of the hour to prevent the disease spread. However, imposing measures such as lockdown would further hamper the management of CVDs. In countries such as India, majority of cardiovascular care is limited to tertiary care setups and as such access to these facilities during periods of lockdown is an issue. In addition, these setups would already be burdened by COVID-19 patients leaving lesser scope for managing other diseases. Patients often fear the risk of contracting the disease while visiting these busy hospitals leading to further delay in seeking medical attention. In patients with STEMI [60], time delays are often expected and with an ever-existing shortage of PPEs and isolation facilities, the option of primary PCI is not feasible. With an ever-increasing spread of the disease especially among health care workers, protection of the doctors and the frontline staff also becomes a huge challenge. In such a scenario, thrombolysis as adopted by the Chinese healthcare system [58] shall be one of the principal treatment modalities in STEMI patients presenting with $12 \mathrm{~h}$ of symptom onset in resource constrained setups. Another group of patients that has to bear the brunt of this pandemic are those with stable CVDs. With most of the elective procedures being deferred, it would create a backlog which would further burden the already strained healthcare system. Another issue in this group of patients is inability to perform routine follow up visits and get medicine refills, a problem which has been partially mitigated by introduction of telemedicine services. However, these are concentrated in urban areas leading to a greater suffering for poor and marginalized people in rural areas.

\section{Long term impact of COVID-19 on cardiovascular system}

Since we are still in the nascent stages of COVID-19 pandemic, data regarding the long-term impact on the cardiovascular system needs to be evaluated. Sparse data exists regarding the longterm impact of SARS-CoV infection on the cardiovascular system. Hospitalization for pneumonia have been shown to increase both short term as well as long term CVD (myocardial infarction, stroke, and fatal coronary heart disease) risk. This has been attributed to a heightened systemic inflammatory and pro-coagulant activity seen in these patients [73]. It has been seen that survivors of SARS epidemic have suffered metabolic derangements over a long follow-up period. A study involving 25 SARS survivors showed that these patients had higher predisposition for hyperlipidemia (68\%), CVA (44\%) and abnormal glucose metabolism $(60 \%)$ over a period of 12 years as compared to healthy volunteers. In addition, these patients had significantly higher lipid levels as compared to controls which had been attributed to the high-dose pulses of methylprednisolone [74]. In a 12-year longitudinal study to determine long-term outcomes in patients with SARS treated with oseltamivir, no significant difference in cardiac parameters was reported among the two groups [75].

\section{Conclusions}

SARS-CoV-2 with its varied epidemiological and biological features has led to a global pandemic which is emerging as one of the greatest challenge mankind has to face. Cardiovascular comorbidities are quite common in COVID-19 patients and have been associated with poor outcomes. Apart from causing ARDS and acute respiratory failure, infection with SARS-CoV-2 often leads to acute cardiac injury, heart failure and cardiac arrhythmias all of which lead to worse outcomes. This highlights the need for an early and detailed cardiac monitoring in COVID-19 patients especially those who are critically ill. In addition, further research is needed detailing the epidemiology, exact pathophysiological mechanism, treatment as well as short- and long-term prognosis in these patients.

\section{References}

1. Zhou P, Yang XL, Wang XG, et al. A pneumonia outbreak associated with a new coronavirus of probable bat origin. Nature 2020;579:270-3.

2. Zhu N, Zhang D, Wang W, et al. A Novel coronavirus from patients with pneumonia in China, 2019. N Engl J Med 2020; 382:727-33.

3. Cucinotta D, Vanelli M. WHO declares COVID-19 a pandemic. Acta Biomed 2020;91:157-60.

4. Dong E, Du H, Gardner L. An interactive web-based dashboard to track COVID-19 in real time. Lancet Infect Dis 2020. Accessed on: 12 April 2020. Doi. 0.1016/S1473-3099(20) 30120-1.

5. Wu D, Wu T, Liu Q, Yang Z. The SARS-CoV-2 outbreak: what we know. Int J Infect Dis 2020;94:44-48. doi: 10.1016/j.ijid. 2020.03.00.

6. WHO. Coronavirus disease. Accessed on: 6 April 2020. Available from: https://www.who.int/emergencies/diseases/ novel-coronavirus-2019

7. Lauer SA, Grantz KH, Bi Q, et al. The incubation period of coronavirus disease 2019 (COVID-19) from publicly reported confirmed cases: estimation and application. Ann Intern Med 2020. doi: 10.7326/M20-0504.

8. Guo YR, Cao QD, Hong ZS, et al. The origin, transmission and clinical therapies on coronavirus disease 2019 (COVID-19) outbreak - an update on the status. Mil Med Res 2020;7:11.

9. Wang D, Hu B, Hu C, et al. Clinical characteristics of 138 hospitalized patients with 2019 Novel Coronavirus-Infected Pneumonia in Wuhan, China. JAMA 2020. doi: 10.1001/jama.2020.1585. [Epub ahead of print] 
10. Wu Z, McGoogan JM. Characteristics of and important lessons from the coronavirus disease 2019 (COVID-19) outbreak in China: summary of a report of 72314 cases from the Chinese Center for Disease Control and Prevention. JAMA 2020. doi: 10.1001/jama.2020.2648. [Epub ahead of print].

11. Shi H, Han X, Jiang N, et al. Radiological findings from 81 patients with COVID-19 pneumonia in Wuhan, China: a descriptive study. Lancet Infect Dis 2020;20:425-34.

12. Yang J, Zheng Y, Gou X, et al. Prevalence of comorbidities in the novel Wuhan coronavirus (COVID-19) infection: a systematic review and meta-analysis. Int J Infect Dis. 2020;94:91-5. doi: 10.1016/j.ijid.2020.03.017. [Epub ahead of print].

13. Grasselli G, Zangrillo A, Zanella A, et al. Baseline characteristics and outcomes of 1591 patients infected With SARS-CoV2 admitted to ICUs of the Lombardy Region, Italy. JAMA 2020 doi: 10.1001/jama.2020.5394. [Epub ahead of print].

14. Zheng YY, Ma YT, Zhang JY, Xie X. COVID-19 and the cardiovascular system. Nat Rev Cardiol 2020;17:259-60. doi: 10.1038/s41569-020-0360-5.

15. Chan JW, Ng CK, Chan YH, et al. Short term outcome and risk factors for adverse clinical outcomes in adults with severe acute respiratory syndrome (SARS). Thorax 2003;58:686-9.

16. Badawi A, Ryoo SG. Prevalence of comorbidities in the Middle East respiratory syndrome coronavirus (MERS-CoV): a systematic review and meta-analysis. Int $\mathrm{J}$ Infect Dis 2016;49:129-33.

17. Al Ghatrif M, Cingolani O, Lakatta EG. The dilemma of coronavirus disease 2019, aging, and cardiovascular disease: insights from cardiovascular aging science. JAMA Cardiol 2020. doi: 10.1001/jamacardio.2020.1329. [Epub ahead of print].

18. Huang C, Wang Y, Li X, et al. Clinical features of patients infected with 2019 novel coronavirus in Wuhan, China. Lancet 2020;395:497-506.

19. Zhou F, Yu T, Du R, et al. Clinical course and risk factors for mortality of adult inpatients with COVID-19 in Wuhan, China: a retrospective cohort study. Lancet 2020;395:1054-62. doi: 10.1016/S0140-6736(20)30566-3.

20. Guo T, Fan Y, Chen M, et al. Cardiovascular implications of fatal outcomes of patients with coronavirus disease 2019 (COVID-19). JAMA Cardiol 2020. doi: 10.1001/jamacardio.2020.1017. [Epub ahead of print].

21. Guan WJ, Ni ZY, Hu Y, et al. Clinical characteristics of Coronavirus Disease 2019 in China. N Engl J Med 2020. Doi: 10.1056/NEJMoa2002032.

22. Chen N, Zhou M, Dong X, et al. Epidemiological and clinical characteristics of 99 cases of 2019 novel coronavirus pneumonia in Wuhan, China: a descriptive study. Lancet 2020;395:507-13.

23. Yang X, Yu Y, Xu J, et al. Clinical course and outcomes of critically ill patients with SARS-CoV-2 pneumonia in Wuhan, China: a single-centered, retrospective, observational study. Lancet Respir Med 2020. doi: 10.1016/S2213-2600(20)300795. [Epub ahead of print].

24. Chen T, Wu D, Chen H, et al. Clinical characteristics of 113 deceased patients with coronavirus disease 2019: retrospective study. BMJ 2020;368:m1091.

25. Yang W, Cao Q, Qin L, et al. Clinical characteristics and imaging manifestations of the 2019 novel coronavirus disease (COVID-19):A multi-center study in Wenzhou city, Zhejiang, China. J Infect 2020;80:388-93.

26. $\mathrm{Xu} X W, \mathrm{Wu} X X$, Jiang $\mathrm{XG}$, et al. Clinical findings in a group of patients infected with the 2019 novel coronavirus (SARSCov-2) outside of Wuhan, China: retrospective case series. BMJ 2020;368:m606.
27. Zhang JJ, Dong X, Cao YY, et al. Clinical characteristics of 140 patients infected with SARS-CoV-2 in Wuhan, China. Allergy 2020. doi: 10.1111/all.14238. [Epub ahead of print].

28. Bhatraju PK, Ghassemieh BJ, Nichols M, et al. Covid-19 in critically ill patients in the Seattle Region - case series. N Engl J Med 2020. doi: 10.1056/NEJMoa2004500. [Epub ahead of print].

29. Arentz M, Yim E, Klaff L, et al. Characteristics and outcomes of 21 critically ill patients with COVID-19 in Washington State. JAMA 2020. doi: 10.1001/jama.2020.4326. [Epub ahead of print].

30. Ruan Q, Yang K, Wang W, et al. Clinical predictors of mortality due to COVID-19 based on an analysis of data of 150 patients from Wuhan, China. Intensive Care Med 2020. doi: 10.1007/s00134-020-05991-x. [Epub ahead of print].

31. Fang Z, Yi F, Wu K, Lai K, et al. Clinical characteristics of Coronavirus Pneumonia 2019 (COVID-19): an updated systematic review. MedRxiv 2020.doi: 10.1101/2020.03.07.20032573.

32. Wu C, Chen X, Cai Y, et al. Risk factors associated with acute respiratory distress syndrome and death in patients with coronavirus disease 2019 pneumonia in Wuhan, China. JAMA Intern Med 2020. doi: 10.1001/jamainternmed.2020.0994. [Epub ahead of print].

33. Lippi G, Lavie CJ, Sanchis-Gomar F. Cardiac troponin I in patients with coronavirus disease 2019 (COVID-19): Evidence from a meta-analysis. Prog Cardiovasc Dis 2020.

34. Clerkin KJ, Fried JA, Raikhelkar J, et al. Coronavirus disease 2019 (COVID-19) and cardiovascular disease. Circulation 2020. doi: 10.1161/CIRCULATIONAHA.120.046941. [Epub ahead of print].

35. Xu Z, Shi L, Wang Y, et al. Pathological findings of COVID19 associated with acute respiratory distress syndrome. Lancet Respir Med 2020;8:420-2.

36. Tavazzi G, Pellegrini C, Maurelli M, et al. Myocardial localization of coronavirus in COVID-19 cardiogenic shock. Eur J Heart Fail 2020. doi: 10.1002/ejhf.1828. [Epub ahead of print].

37. Saini HK, Xu YJ, Zhang M, et al. Role of tumour necrosis factor-alpha and other cytokines in ischemia-reperfusion-induced injury in the heart. Exp Clin Cardiol 2005;10:213-22.

38. He XW, Lai JS, Cheng J, et al. [Impact of complicated myocardial injury on the clinical outcome of severe or critically ill COVID-19 patients].[Article in Chinese]. Zhonghua Xin Xue Guan Bing Za Zhi 2020;48:E011. [Epub ahead of print]

39. Zeng JH, Liu YX, Yuan J, et al. First case of COVID-19 infection with fulminant myocarditis complication: a case report and insights. preprints. 2020; doi: 10.20944/preprints202003. 0180.v1.

40. Hu H, Ma F, Wei X, Fang Y. Coronavirus fulminant myocarditis saved with glucocorticoid and human immunoglobulin. Eur Heart J 2020. pii: ehaa190. doi: 10.1093/eurheartj/ehaa190. [Epub ahead of print].

41. Hua A, O'Gallagher K, Sado D, Byrne J. Life-threatening cardiac tamponade complicating myo-pericarditis in COVID-19. Eur Heart J 2020 Mar 30. pii: ehaa253. doi: 10.1093/eurheartj/ehaa253. [Epub ahead of print].

42. Inciardi RM, Lupi L, Zaccone G, et al. Cardiac involvement in a patient with Coronavirus Disease 2019 (COVID-19). JAMA Cardiol 2020. doi: 10.1001/jamacardio.2020.1096. [Epub ahead of print].

43. Alhogbani T. Acute myocarditis associated with novel Middle east respiratory syndrome coronavirus. Ann Saudi Med 2016;36:78-80.

44. Ma KL, Liu ZH, Cao CF, et al. COVID-19 myocarditis and 
severity factors: an adult cohort study. MedRxiv 2020. doi: 10.1101/2020.03.19.20034124.

45. Hui H, Zhang Y, Yang X, et al. Clinical and radiographic features of cardiac injury in patients with 2019 novel coronavirus pneumonia. MedRxiv 2020. doi: 10.1101/2020.02.24. 20027052.

46. Yu CM, Wong RS, Wu EB, et al. Cardiovascular complications of severe acute respiratory syndrome. Postgrad Med J 2006;82:140-4.

47. Giudicessi JR, Noseworthy PA, Friedman PA, Ackerman MJ. Urgent guidance for navigating and circumventing the QTcprolonging and torsadogenic potential of possible pharmacotherapies for coronavirus disease 19 (COVID-19). Mayo Clin Proc 2020. doi: 10.1016/j.mayocp.2020.03.024 [Epub ahead of print].

48. Driggin E, Madhavan MV, Bikdeli B, et al. Cardiovascular considerations for patients, health care workers, and health systems during the coronavirus disease 2019 (COVID-19) pandemic. J Am Coll Cardiol 2020. doi: 10.1016/j.jacc.2020. 03.031. [Epub ahead of print].

49. Xie Y, Wang X, Yang P, Zhang S. COVID-19 complicated by acute pulmonary embolism. Radiology: Cardiothoracic Imaging 2020. doi: 10.1148/ryct.2020200067.

50. Danzi GB, Loffi M, Galeazzi G, Gherbesi E. Acute pulmonary embolism and COVID-19 pneumonia: a random association? Eur Heart J 2020. doi: 10.1093/eurheartj/ehaa254. [Epub ahead of print].

51. Tang N, Li D, Wang X, Sun Z. Abnormal coagulation parameters are associated with poor prognosis in patients with novel coronavirus pneumonia. J Thromb Haemost 2020;18:844-7.

52. Shorr AF, Thomas SJ, Alkins SA, Fitzpatrick TM, et al. Ddimer correlates with proinflammatory cytokine levels and outcomes in critically ill patients. Chest 2002;121:1262-8.

53. Gunther A, Mosavi P, Heinemann S, et al. Alveolar fibrin formation caused by enhanced procoagulant and depressed fibrinolytic capacities in severe pneumonia. Comparison with the acute respiratory distress syndrome. Am J Respir Crit Care Med.2000;161:454-62.

54. Bone RC, Grodzin CJ, Balk RA. Sepsis: a new hypothesis for pathogenesis of the disease process. Chest 1997;112:235-43.

55. Shanghai Clinical Treatment Expert Group for COVID-19. [Comprehensive treatment and management of coronavirus disease 2019: expert consensus statement from Shanghai]. [Article in Chinese]. Chin J Infect 2020.38 [published online ahead of print].

56. Tang N, Bai H, Chen X, et al. Anticoagulant treatment is associated with decreased mortality in severe coronavirus disease 2019 patients with coagulopathy. J Thromb Haemost 2020;18:1094-99. doi: 10.1111/jth.14817.

57. Li T, Lu H, Zhang W. Clinical observation and management of COVID-19 patients. Emerg Microbes Infect 2020;9:687-90.

58. Jing ZC, Zhu HD, Yan XW, Chai WZ, et al. Recommendations from the Peking Union Medical College Hospital for the management of acute myocardial infarction during the COVID-19 outbreak. Eur Heart J 2020. doi: 10.1093/eurheartj/ehaa258 [Epub ahead of print].

59. Welt FGP, Shah PB, Aronow HD, et al. Catheterization laboratory considerations during the Coronavirus (COVID-19) pandemic: From ACC's Interventional Council and SCAI. J Am
Coll Cardiol 2020. doi: 10.1016/j.jacc.2020.03.021. [Epub ahead of print].

60. Tam CF, Cheung KS, Lam S, et al. Impact of coronavirus disease 2019 (COVID-19) outbreak on ST-segment-elevation myocardial infarction care in Hong Kong, China. Circ Cardiovasc Qual Outcomes 2020;13:e006631.

61. Nagachinta T, Sawanpanyalert N, Chanprasert P. A review of influenza. J Infect Dis Antimicrob Agents 2009;26:115-32.

62. Shah PB, Welt FGP, Mahmud E, et al. Triage considerations for patients referred for structural heart disease intervention during the coronavirus disease 2019 (COVID-19) pandemic: An ACC /SCAI Consensus Statement. JACC Cardiovasc Interv 2020. doi: 10.1016/j.jcin.2020.04.001. [Epub ahead of print].

63. Sommerstein R, Gräni C. Rapid response: re: preventing a covid-19 pandemic: ACE inhibitors as a potential risk factor for fatal Covid-19. BMJ 2020;368:m810.

64. Fang L, Karakiulakis G, Roth M. Are patients with hypertension and diabetes mellitus at increased risk for COVID-19 infection? Lancet Respir Med 2020;8:e21.

65. Vaduganathan M, Vardeny O, Michel T, et al. Reninangiotensin-aldosterone system inhibitors in patients with Covid-19. N Engl J Med 2020;382:1653-9.

66. Liu Y, Yang Y, Zhang C, et al. Clinical and biochemical indexes from 2019-nCoV infected patients linked to viral loads and lung injury. Sci China Life Sci 2020;63:364-74.

67. Kuba K, Imai Y, Rao S, et al. A crucial role of angiotensin converting enzyme 2 (ACE2) in SARS coronavirus-induced lung injury. Nat Med 2005;11:875-9.

68. Yan Y, Liu Q, Li N, et al. Angiotensin II receptor blocker as a novel therapy in acute lung injury induced by avian influenza A H5N1 virus infection in mouse. Sci China Life Sci 2015;58:208-11.

69. European Society of Cardiology. Position Statement of the ESC Council on Hypertension on ACE-Inhibitors and Angiotensin Receptor Blockers. Accessed on: 8 April 2020. Available from: https://www.escardio.org/Councils/Councilon-Hypertension-(CHT)/News/position-statement-of-the-esccouncil-on-hypertension-on-ace-inhibitors-and-ang.

70. European Society of Hypertension. ESH letter Covid-19 Available from: https:/www.eshonline.org/spotlights/esh-letter-covid-19-2/. Accessed on: 8 April 2020.

71. Li F, Cai J, Dong N. First cases of COVID-19 in heart transplantation from China. J Heart Lung Transplant 2020. doi: 10.1016/j.healun.2020.03.006.

72. Zong-Li Ren RH, Zhi-Wei Wang, et al. Epidemiological and clinical characteristics of heart transplant recipients during the 2019 Coronavirus outbreak in Wuhan, China: a descriptive survey report. J Heart Lung Transplant 2020. doi: 10.1016/j.healun.2020.03.008.

73. Corrales-Medina VF, Alvarez KN, Weissfeld LA, et al. Association between hospitalization for pneumonia and subsequent risk of cardiovascular disease. JAMA 2015;313:264-74.

74. Wu Q, Zhou L, Sun X, et al. Altered lipid metabolism in recovered SARS patients twelve years after infection. Sci Rep 2017;7:9110.

75. Guo L, Han Y, Li J, et al. Long-term outcomes in patients with severe acute respiratory syndrome treated with oseltamivir: a 12year longitudinal study. Int J Clin Exp Med 2019;12:12464-71. 